\title{
Knowledge and Hygiene Practice of mothers of under- five children regarding Diarrhoea: A study in Bargarh District, Odisha.
}

\author{
Dr. Chandrashree Lenka ${ }^{1}$, Tripti Kumari ${ }^{2}$, Trupti Pradhan ${ }^{3}$ \\ ${ }^{1}$ P.G. Department of Home Science, Sambalpur University, Odisha, India-768019 \\ ${ }^{2}$ P.G. Department of Home Science, Sambalpur University, Odisha, India-768019 \\ ${ }^{3}$ P.G. Department of Home Science, Sambalpur University, Odisha, India-768019
}

${ }^{3}$ truptipra5@gmail.com

\begin{abstract}
Diarrhoea continues to be a major cause of morbidity and mortality among under-five children. Knowledge of mothers regarding signs and symptoms, mode of spread, and healthy practices like exclusive breast feeding up to 6 months, immunization, ORS, good sanitary conditions are essential to prevent morbidity and mortality related to diarrhoea. The present study was conducted with an objective of assessing knowledge and practice of mothers of under-five children regarding management of diarrhoea. A cross-sectional hospital based study was carried out in Bargarh district of Odisha. 120 mothers and their children were selected randomly from the diarrhoea ward of Govt. Hospital of Bargarh district of Odisha for the present study. Result of the study revealed that majority of the mothers were in the age group of 21-30 years and 36.67\% mothers had high school level of education. Most of the mothers belonged to lower middle socio-economic class. More than half of participants lacked adequate knowledge regarding danger signs of diarrhoea, and preparation of ORS. Significant association was found between overall knowledge of mothers in managing diarrhoea with their level of education and socio-economic class. It was observed that most of the mothers practiced good personal hygiene during diarrhoea of the children. Self prepared food was used by $90.83 \%$ of mothers during diarrhoea where as only $52.5 \%$ of mothers prepare special food for their children. A strong significant association was found between socio-economic class, education level of mothers with hygiene practice during diarrhoea $(P=0.042)$ in this study. So health education and behaviour change communication should be prioritized to mitigate problems related to diarrhoea
\end{abstract}

Keywords: Knowledge, hygiene Practice, Under-five children, Diarrhoea

\section{Introduction}

Diarrhoea is the second most common cause of morbidity and mortality among under 5 children worldwide. It is defined as the passage of loose, liquid or watery stools more than three times a day [1]. Globally, there are nearly 1.7 billion cases of diarrheal disease and 760,000 deaths in children under 5 every year due to diarrhoea. In India, diarrhoea accounts 
for nearly 212,000 under five deaths annually. [2]. Death due to diarrhoea can be prevented by prompt supplementation of salt sugar solution (SSS) at household level or by use of commercial ORS and through integrated management of childhood illness (IMCI) [3].

One of the prime goals of millennium development goals \& National health mission (India) is to accelerate efforts towards reduction of childhood mortality due to diarrhoea among under five. To address this issue effectively, ministry of health and family welfare, India in conjunction with UNICEF has initiated a nationwide campaign known as intensified diarrhoea control fortnight (IDCF), which is conducted from $28^{\text {th }}$ July to 8th August of every year from 2014 with the ultimate aim of 'zero child deaths due to childhood diarrhoea'. IDCF also aims to achieve improved coverage of essential life-saving commodity of ORS, zinc dispersible tablets and practice of appropriate child feeding practices during diarrhoea. [4]

Primary preventive measures to control diarrhoea related morbidities and mortalities are use of clean water, hand washing, good cooking practices, exclusive breast feeding, immunization, sanitary disposal of excreta, use of latrines and good sanitary and hygienic practices [5]. However, poor socioeconomic status, lack of knowledge among caregivers, and failure to provide therapy in time are hindering factors in preventing diarrheal deaths [6)]. So mothers knowledge and hygiene practice plays an most important role in to reducing diarrhoeal disease among children.

Bargarh is a unique district in Odishawith high literacy rate, better health indices, and health-care facilities. In this context, the present study was conducted to determine the knowledge, and hygiene practice of mothers of under-five children regarding the diarrheal illness in Bargarh District of Odisha.

\section{Methodology:}

A hospital based observational study was carried out during January to April 2020 in Government District Hospital Bargarh, Odisha. All mothers of under-five children, who admitted in the department of Pediatrics within the study period were interviewed. The children who visited hospital with care-takers other than mother were excluded from the study. After obtaining written consent from the mothers, data was collected from 120 mothers by face-to-face interviews using pretested, self-designed questionnaire containing questions related to their socio-demographic variables, question on knowledge of diarrhoea, food hygiene behaviour, food preparation and hygiene practices about diarrhoea management. The socio-economic class was assessed by using modified Kuppuswamy socioeconomic scale updated for the year 2021. The collected information was tabulated and analyzed using frequency, percentage and Chi-square test. 


\section{Results}

\section{Demographic Profile}

Table No.-1 Demographic profile of under-five children.

\begin{tabular}{|l|l|l|l|}
\hline Variables & Category & Frequency & Percentage \\
\hline Age & $6-12$ month & 22 & 18.33 \\
\cline { 2 - 4 } & $1-3$ year & 56 & 46.67 \\
\cline { 2 - 4 } & $3-5$ year & 42 & 35 \\
\hline \multirow{5}{*}{ Gender } & Male & 74 & 61.67 \\
\cline { 2 - 4 } & Female & 46 & 38.33 \\
\hline \multirow{5}{*}{ Caste } & Hindu & 116 & 96.67 \\
\cline { 2 - 4 } & Muslim & Nil & Nil \\
\cline { 2 - 4 } & Cristian & 4 & 3.33 \\
\hline Type of family & General & 16 & 13.33 \\
\cline { 2 - 4 } & OBC & 45 & 37.5 \\
\cline { 2 - 4 } & SC & 53 & 44.17 \\
\cline { 2 - 4 } & ST & 6 & 5 \\
\hline Duration of admission & Joint & 63 & 52.5 \\
\hline & Nuclear & 57 & 47.5 \\
\hline & 1day & 53 & 44.17 \\
\cline { 2 - 4 } & 2 days & 47 & 39.17 \\
\cline { 2 - 4 } & 3 days & 14 & 11.67 \\
\cline { 2 - 4 } & 4 days & 06 & 5 \\
\hline
\end{tabular}

Table-1revealed demographic profile of the under-five children suffering from diarrhoea. It was observed that majority $46.67 \%$ were under $1-3$ year, $35 \%$ were in $3-5$ year and $18.33 \%$ belonged to 6-12 months. $61.67 \%$ were male and $38.33 \%$ were female. Majority (96.67\%) were Hindu and only $3.33 \%$ were Christian. Most $(44.17 \%)$ of the respondents were SC category. $52.5 \%$ were belonged to joint family and $47.5 \%$ were from nuclear. Majority (44.17\%) of patients admitted for one day in the hospital followed by $39.17 \%$ for two days and $11.67 \%$ for three days [Table 1]. 
Figure 1: Socio-demographic characteristics of mothers.

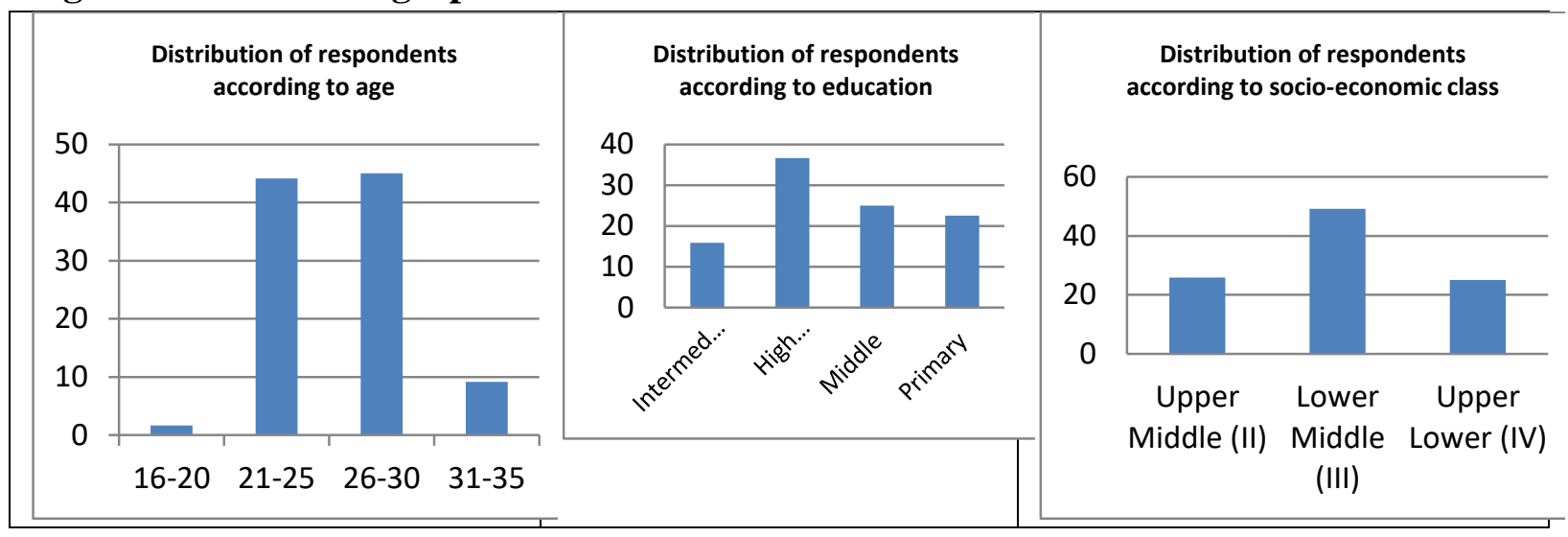

Figure -1 reveals socio-demographic characteristics the mothers. Most (45\%) of mothers were in the age group of 26-30 years and only $1.67 \%$ were in age group of 16-20 years. Information on education of mothers revealed that $36.67 \%$ completed high school education and $18.33 \%$ were educated up to intermediate. Majority of the mothers $(49.17 \%)$ belonged to lower middle class.

Table No. 2: Assessment of knowledge of mothers regarding Diarrhoea.

\begin{tabular}{|l|l|l|l|}
\hline Sl.No. & Characteristics & Right answered by mothers & $\%$ \\
\hline & Definition of diarrhea & 35 & 29.17 \\
\hline & Diarrhoeal cause & 51 & 42.5 \\
\hline & Diarrhoeal danger signs & 17 & 14.17 \\
\hline & How is ORS prepared? & 35 & 29.17 \\
\hline & How often should ORS be given? & 12 & 10 \\
\hline & How long should the mixed ORS last? & 88 & 73.33 \\
\hline & Fluids and feeds during diarrheal illness & 82 & 68.33 \\
\hline & Prevention measures & 59 & 49.17 \\
\hline
\end{tabular}

Table -2 describes mothers' knowledge about diarrhoea and its preventive and measures. Most of the $(29.17 \%)$ mother's defined diarrhoea correctly as the passing of loose stool 3 or more times per day. $42.5 \%$ of mothers thought that diarrhoea is caused by drinking contaminated water. Very few mothers had correct knowledge regarding danger sign of diarrhoea. Only $29.17 \%$ mothers knew about the recommended volume of water for mixing a sachet of ORS (i.e., $1000 \mathrm{ml}$. of water to 1 sachet of ORS or proper preparation method). Only $10 \%$ of the mothers aware about ORS should be given whenever child want to drink, while $73.33 \%$ respondents replied that ORS should be mixed within last 24 hour. It was observed that most $(68.33 \%)$ of the mothers feed ORS to their children during diarrheal illness. $49.17 \%$ mothers had correct knowledge about preventive measures of diarrhoea during childhood. 
Table No. 3: Association between Socioeconomic status, education and knowledge of mothers regarding diarrhoea.

\begin{tabular}{|c|c|c|c|c|}
\hline Socio-economicStatus & Poor & Average & Good & $P$ value \\
\hline Upper Middle & 3 & 17 & 7 & \multirow[t]{3}{*}{0.013} \\
\hline Lower Middle & 27 & 23 & 13 & \\
\hline Upper Lower & 16 & 8 & 6 & \\
\hline \multicolumn{5}{|l|}{ Mother's Education } \\
\hline Intermediate & 3 & 10 & 6 & \multirow[t]{3}{*}{0.021} \\
\hline High School & 17 & 16 & 11 & \\
\hline Middle & 10 & 17 & 3 & \\
\hline
\end{tabular}

There were eight questions in the questionnaire to assess knowledge level of mothers regarding diarrhoea and its management. Each correct response was given a point of 1 and wrong response was given 0 point. A score of 0-2, 3-5 and 6-8 was considered as having poor, average and good knowledge respectively. Socio-economic status classified according to the Kuppu Swamy Scale(2020). Statistically significant $(\mathrm{P}=0.013)$ association between socioeconomic status and knowledge of mothers regarding diarrhoea was observed in this study. This indicates that a mother with high socioeconomic status has better knowledge about diarrhoea and its management. Statistically significant association was also observed between education of mothers and knowledge regarding diarrhoea $(\mathrm{P}=0.021)$. Thus it can be concluded that level of education and economic condition of mothers had significant role in managing childhood diarrhoea.

Table No.4: Hygiene Practices of mothers during diarrhoea of their children.

\begin{tabular}{|l|l|l|}
\hline Practices & Frequency & Percentage \\
\hline Use of private toilet & 94 & 78.33 \\
\hline Children always wash hand with soap and water after toilet. & 108 & 90 \\
\hline Children always wash hand with soap before eating. & 103 & 85.83 \\
\hline Mother always hand washing with soap and water after toilet. & 114 & 95 \\
\hline Mother always wash hand with soap before feeding. & 101 & 84.17 \\
\hline Hygiene during Food preparation & & \\
\hline Always wash hand with soap before food preparation & 87 & 72.5 \\
\hline Always wash hand with water before food preparation. & 96 & 80 \\
\hline Always use separate utensils for raw and cooked food. & 61 & 50.83 \\
\hline Always use table for preparation of food. & 46 & 38.33 \\
\hline Always use closed domestic waste disposal. & 112 & 93.33 \\
\hline Food-hygiene behavior & & \\
\hline Food cooked by mother. & 109 & 90.83 \\
\hline Cooked special food for child. & 57 & 47.5 \\
\hline Food holding time before < 1 hour eaten. & 49 & 40.83 \\
\hline
\end{tabular}




\begin{tabular}{|l|l|l|}
\hline Every time reheat the food before feeding child. & 55 & 45.83 \\
\hline Feeding child with warm or hot food. & 90 & 75 \\
\hline Store food in covered or closed pan. & 95 & 79.17 \\
\hline Wash utensils inside the home. & 94 & 78.33 \\
\hline Washed utensils with flowing tap water. & 89 & 74.17 \\
\hline Water source and safe drinking water & & \\
\hline Use supply water. & 82 & 68.33 \\
\hline Drink purified water. & 47 & 39.17 \\
\hline Covered or closed water storage. & 97 & 80.33 \\
\hline
\end{tabular}

Information on hygiene practice of mothers during diarrhoea showed that out of 120 mother's majority $(78.33 \%)$ of mothers used private toilet. Most of the children washed their hands with soap after toilet, $85.83 \%$ children washed hand with soap before eating, $95 \%$ mothers always washed their hands with soap and water after toilet. 84.17\% mothers washed their hands with soap before feeding to children. Information on food hygiene behaviour of mothers showed that $72.5 \%$ mothers washed hands with soap whereas $80 \%$ mothers washed their hands only with water before food preparation. Maximum (93.33\%) mothers always used close container for domestic waste disposal. Data on hygiene practice during food preparation revealed that $90.83 \%$ mothers prepared food by themselves for their children and 75\% mothers fed warm or hot food to their children. $79.17 \%$ mothers covered or closed store food. Regarding safe drinking water and their sources, 68.33\% mothers used PHD supply water for purpose of drinking whereas only $39.17 \%$ mothers used purified water for drinking.

Table No. 5: Association between age group, education, socioeconomic status and hygiene practices regarding diarrhoea in mothers.

\begin{tabular}{|c|c|c|c|c|}
\hline \multirow[t]{2}{*}{ Category } & \multicolumn{3}{|c|}{ Hygiene Practices } & \multirow[t]{2}{*}{$\mathrm{P}$} \\
\hline & Poor & Average & Good & \\
\hline \multicolumn{4}{|l|}{ Age group } & \multirow[t]{3}{*}{0.641} \\
\hline $16-26$ & 2 & 38 & 15 & \\
\hline $26-35$ & 4 & 40 & 21 & \\
\hline \multicolumn{4}{|l|}{ Educational Status } & \multirow[t]{3}{*}{0.0421} \\
\hline College education & 1 & 15 & 3 & \\
\hline School education & 13 & 48 & 40 & \\
\hline \multicolumn{4}{|c|}{ Socioeconomic Status } & \multirow[t]{3}{*}{0.012} \\
\hline Lower & 4 & 64 & 8 & \\
\hline Higher & 3 & 27 & 14 & \\
\hline
\end{tabular}

Hygiene Practices of mothers regarding diarrhoea illness were categorized as poor, average and good by asking twenty four questions. Each correct practice was given a point 1 and wrong practice was given 0 point. A score of $<12,12-18$ and $<18$ was considered as having poor, average and good hygiene practice respectively. No significant association between age 
and hygiene practices of mothers during diarrhoea was observed in this study. However statistically significant association between educational status $(\mathrm{P}=0.042)$, socio-economic condition $(\mathrm{P}=0.012)$ of mothers with their hygiene practices during diarrhoea was observed in this study. Thus it can be concluded that education and economic condition of mothers has a pivotal role in diarrhoea management in children.

\section{Discussion}

Childhood diarrhoea is the most common cause of morbidity and mortality among under five children. Result of the present study revealed that majority of children (46.67\%) in age group 1-3 years were suffering from diarrhea and higher incidence of diarrhoea was found among male children $(61.67 \%)$ in comparison to female $(38.33 \%)$ which is similar to the findings of Adeleke. et al (2019) and Padhy et al (2017). Present study revealed that majority of mothers (45\%) were in age group 26-30 years and most of them belonged to lower socioeconomic class. Similar finding was also reported by Mahor. R. G (2013). Mothers were aware about diarrhoea but the level of knowledge about definition, cause, danger sign and preventive measures regarding diarrhoea was very poor. The poor knowledge among the mothers about preparation and proper use of ORS during diarrhea was found in this study. Similar findings was also observed by Ansari. M. et al (2011) and Shah et al (2010). Regarding hygiene practices behaviour of mothers, 95\% of mothers always washed their hand with soap after defecation, $84.17 \%$ washed their hands with soap before feeding to children and $72.5 \%$ wash their hands with soap before food preparation. Most of the (78.33\%) mothers were using private toilet. Majority of mothers $(68.33 \%)$ used PHD supply water directly for drinking purpose, whereas only $39.17 \%$ used purified drinking water. Information on storage of drinking water, majority (80.33\%) covered or closed water storage container whereas $19.17 \%$ kept the water container open. Similar finding was also observed by Workie H.M.(2018).

\section{Conclusion}

The present study was conducted with objectives to assess the knowledge and hygiene practices by mothers of under five children with diarrhoea. The above study concluded that overall knowledge about diarrhoea and its management at home was poor among the mothers. Although mothers were aware about diarrhoea and its management at household level their knowledge pertaining to vital issues such as danger signs of dehydration, actual role of oral rehydration fluids during diarrhoea, correct and complete preparation of ORS solutions and the correct amount of ORS solution to be given to children during diarrhoea was very poor. A significant association between education of mothers with knowledge regarding diarrhea $(\mathrm{P}=0.021)$ and appropriate hygiene practices during diarrhoea management $(\mathrm{P}=0.042)$ of mothers found in this study. Thus extensive educational intervention and behavior change communication for parents is need of the hour. 


\section{Acknowledgements}

I would like to thank Dr. Chandrashree Lenka, H.O.D. P. G. Department Home

Scioence,Sambalpur University for her guidance to prepare the paper.

Funding: No funding sources

Conflict of interest: None declared

\section{References}

[1]. Rokkappanavar K. K, Nigudgi S. R and Ghooli S. (2016). A study on knowledge and practice of mothers of under-five children regarding management of diarrhoea in urban field practice area of MRMC, Kalaburagi, Karnataka., India.. Int J Community Med Public Health, 3(3), pp.705-710.

[2]. Ashraf A, Bhat M. A and Mahrukh. (2017). Childhood diarrhoea: assessment of knowledge, attitude and practices among mothers attending the tertiary care hospital:an observational analytical study. Int J Community Med Public Health, 4(4), pp.1219-1222.

[3]. Bhutta ZA. (2016). Acute Gastroenteritis in Children. Nelson Text Book of Pediatrics, 20th ed. Philadelphia. Elsevier, pp. 1854-74.

[4]. WHO, UNICEF (2009), Diarrhoea: Why children are still dying and what can be done.

[5]. Munos M. K, Walker C. L and Black R. E. (2010). The effect of oral rehydration solution and recommended home fluids on diarrhoea mortality. International Journal of Epidemiology, 39(i), pp.75-87.

[6]. Sarkar R, Gladstone BP, Warier JP, Sharma SL, Raman U, Muliyil J, et al., (2016). Rotavirus and other diarrheal disease in a birth cohort from Southern Indian community. Indian Pediatric, 53,pp.583-8.

[7]. Adeleke A.I. and Mhlaba T. (2019). Maternal Knowledge, Attitudes and Practices towards Prevention and Management of Child Diarrhea in Urban and Rural Maseru, Lesotho. International Journal of TROPICAL DISEASE \& Health, 36(2), pp. 1-20.

[8]. Mahor G.R. (2013). Knowledge and attitudes of mothers regarding use of Oral Rehydration Solution in management of diarrhea. Asian Journal of Biomedical and Pharmaceutical Sciences, 3(22), pp. 6-8.

[9]. Ansari. M, Ibrahim M. I. M. and Shankar P. R. (2011). A survey of mothers' knowledge about childhood diarrhea and its management among a marginalized community of Morang, Nepal. Australasian Medical Journal, 4(9), pp. 474-479.

[10]. Shah M. S, Ahmad A, Khalique NN, Khan IM, Ansari MA, Khan Z.. (2010). Do the mothers in rural Aligarh know about home based management of acute diarrhoea? Fronteirs in Life Sciences. Basic Appl MAASCON-1.3(2).pp. 76-80.

[11]. Workie H.M, Sharifabdilahi A. S and Addis E. M. (2018). Mothers' knowledge, attitude and practice towards the prevention and home-based management of diarrheal disease among under-five children in Diredawa, Eastern Ethiopia-A cross-sectional study. BMC Pediatrics, 18,pp.358.

[12]. Saleem S. M and Jan S. S. (2021). Modified Kuppuswamy socioeconomic scale updated for the year 2021. Indian Journal of Forensic and Community Medicine, 8(1), pp.1-3. 